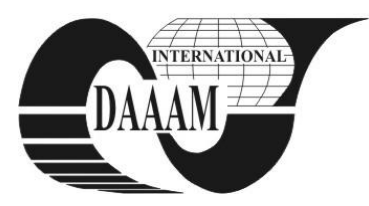

Annals of DAAAM for 2012 \& Proceedings of the 23rd International DAAAM Symposium, Volume 23, No.1, ISSN 2304-1382 ISBN 978-3-901509-91-9, CDROM version, Ed. B. Katalinic, Published by DAAAM International, Vienna, Austria, EU, 2012 Make Harmony between Technology and Nature, and Your Mind will Fly Free as a Bird

\title{
THE EVOLUTION OF RESEARCH ON THE DETERMINING FACTORS OF FINANCIAL STRUCTURE - CHALLENGES AND TRAJECTORIES
}

\author{
TUDOSE, M[ihaela] B[rindusa] \& GOLBAN, R[adu] - E[ugen]
}

\begin{abstract}
The aim of this paper is to examine the determining factors of firms' capital structure, in order to highlight the state of current knowledge on the theoretical and applied level (including in terms of methodology) and to assess progress in the sphere of scientific research. Viewed dynamically, it is clearly apparent that the literature in the field has been enriched by extensive theoretical and empirical debates; most studies have developed analytical reference diagrams vital for identifying and quantifying the impact of the various influencing factors of capital structure; nevertheless, as the analysis points out, earlier studies exhibited certain limitations which emerged as challenges for subsequent debates. Based on a summary (both descriptive and critical) of the principles, stages and phases, as well as of the methods, techniques and instruments related to the research and knowledge of the determinants of firms' capital structure, the study suggests that we are witnessing progress in scientific research and thereby the application of ever more complex methodologies. The study delivers a threefold benefit: scientific, theoreticalmethodological and practical.
\end{abstract}

Keywords: debt ratio, financial structure, determining factors of financial structure, research methodology

\section{INTRODUCTION}

The earliest research in the field of corporate finance dates back to the end of the 1950's, when the idea of the irrelevance of capital structure was introduced. In the 1960s-1970s, research was oriented towards the analysis of benefits and costs deriving from leverage; these works were grouped under the generic headline of static tradeoff theory, whose underlying notion is that firms set a target debt ratio which they aim to achieve. In the mid1970s, research turned to agency costs, focusing on two categories of conflicts of interest: between managers and shareholders, on the one hand, and between creditors and shareholders, on the other. In the first half of the 1980s, the emphasis was largely placed on information asymmetries among investors and firms, outlining the pecking order theory. The starting point in laying the grounds for the new theory was the assumption that - less informed - investors need an incentive to invest in risky securities; consequently, the idea emerged that internally generated funds can represent the best financing option, whereas the use of own external capital would be the last financing alternative. In the latter half of the 1980s, financial theories described the corporate finance structure based on the factors associated with industrial strategy and corporate organisation. Research during the 1990s was marked by the focus on the disjunctivehypothetical reasoning, with researchers being interested in providing arguments in favour of or against the two theories proposed, i.e. trade-off theory and pecking order theory, respectively.
The idea put forward 10 years ago, asserting that "there is no universal theory of the debt-equity choice, and no reason to expect one" (Myers, 2001), reoriented research to the level of empirical analyses of the determinants of capital structure.

Studies have analysed the capital structure of firms located in various countries, taking into account their specific influencing factors. Although the ultimate aim of research on this topic was the same (i.e. identifying an optimal debt ratio that is in line with stakeholders' expectations), disagreement persists over the factors that significantly impact the capital structure of an individual firm. With the rising interest in identifying and accounting for the influence of the various determinants of corporate capital structure, one may notice that developments in the area of scientific research have set into action ever more complex methodologies.

The main objective of the present study is to examine the evolution of debates revolving around the determinants of firms' capital structure and to highlight the progress achieved in scientific research. The operational objectives, circumscribed to the goal of capturing the evolving trends in specific research, are aimed at: identifying the factors serving to establish the financing mix; analysing the architectural structure of specific debates; and distinguishing the drivers that have triggered scientific research in the field. In order to achieve these objectives, we have focused not only on quantitative aspects (the number of dependent and independent variables, the number of assumptions, the size of the sample under review, etc.) but also on qualitative ones (the theoretical grounds, the nature of the data, the quality of analyses, the manner of testing the assumptions, etc.).

The underlying method of this paper was the comparative analysis of the most representative works in the field. The originality element that we undertake is to achieve a summary (both descriptive and critical) of the principles, stages and phases, as well as of the methods, techniques and instruments related to the research and knowledge of the determinants of corporate capital structure. Hence, we have had the opportunity to prepare a paper that delivers a three-fold benefit: scientific (as it reflects the current state of knowledge in the field and contributes to perfecting scientific forecasting methods which enable the proper adjustment of capital structure), theoretical-methodological (as it provides a framework methodology that enables further research on this theme) and practical (as it can serve as a reference for financial decision-makers to facilitate the optimisation of firms' financial structure). 
The references we drew on in order to define the architecture of this study were: the temporal benchmark (focusing on the evolution over time) and the content benchmark (focusing on new contributions in research). Accordingly, the study is organised as follows: section 2 introduces the determining factors of capital structure; section 3 presents the methodological references of specific research in the field; the last section summarises findings and advances some conclusions.

\section{THE DETERMINING FACTORS OF CORPORATE CAPITAL STRUCTURE}

Modern theories of capital structure (trade-off theory, pecking order theory, agency theory) and econometric models formed the basis of researchers' pursuits aiming to evaluate the impact of the various factors that affect the firm's capital structure. In the earliest stages of research, the emphasis was placed on the analysis of determinants of capital structure at firm level; subsequently, research expanded by incorporating in analyses factors specific to the various industries. Later, it was demonstrated that the choice of capital structure is also affected by macro-level factors - such as the institutional environment and a country's infrastructure.

Studies that explore the role of variables specific to companies, industries and countries in defining the firms' financing policies acknowledge the fact that all three factor categories shape firms' capital structure. Notwithstanding this observation, we estimate that among the three categories of factors, the firm-specific ones wield the dominant influence over the capital structure.

Since firm-specific variables have the broadest implications on financial leverage, financial managers must particularly focus on such variables when making financing-related decisions. Most studies examine the influence of the following variables:

a) asset tangibility - which is assessed based on the share of fixed assets in the total assets;

b) profitability - determined based on the ratio of earnings before taxes and total assets; although widely recognised as a factor that exerts considerable influence over the financial structure, there is a lack of consensus in terms of theoretical formulations - as regards the nature and meaning of this particular influence;

c) firm size - the assessment of firm size is performed by considering two benchmarks: the number of employees (Bass et al., 2010) or the sales logarithm (Kayo \& Kimura, 2011); as regards the theoretical grounding, there are common views on the relationship between firm size and leverage;

d) growth opportunities - two alternative methods are used to determine and assess this indicator: the ratio of the firm's total market value (namely, the sum of debt and equity marked-to-market) and the value of total assets; the ratio of turnover growth rate and the growth of total assets;

e) external finance weighted average market-to-book (EFWA) - according to M. Baker \& J. Wurgler (2002), firms prefer issuing equity when the market valuation is higher (integrating this issue with the market timing theory). A. Hovakimian (2006) considers EFWA to be a variable which provides information on the firm's development prospects;

f) the probability of financial distress - is estimated using the Altman's Z-score as modified by MackieMason; the vast majority of studies agree that companies that are financially sound tend to have lower debt levels (Byoun, 2008; Kayo \& Kimura, 2011);

g) capital intensity - is assessed based on the ratio of the employment rate and fixed assets, as proxy for the operating leverage (Prahalathan, 2010); a high value of the indicator suggests an increased risk of variation of future earnings;

h) non-debt tax shields - this category incorporates, most often, depreciations; if firms also have further tax deductible items (providing a tax shield), other than their debts, then the leverage effect is low (Prahalathan, 2008);

Industry-specific determining factors are considered to be external to the firm, i.e. factors which originate in the firm's external environment. According to the scope of the research, studies which incorporate industry-level determinants in their analyses of capital structure can be grouped as follows: studies which were confined to classifying the industries and analysing the determinants of capital structure (which constituted the starting point for the earliest research); studies which not only classified industries but also characterised them (e.g. more recent studies by MacKay \& Phillips, 2005; Kayo \& Kimura, 2011).

a) Industry dynamism. Initial studies associated the concept of industry dynamism with a firm's business risk (reflecting the variability of expected future revenue) or with the variability of profit (which suggests the firm's future ability to meet both its fixed obligations and those related to debt payments) (Kayo \& Kimura, 2011).

b) Environmental munificence been defined as the capacity of the environment to sustain durable growth (through an abundance of resources). Without directly researching the link between environmental munificence and the firm's leverage, some authors indicated that environments characterised by high levels of munificence feature plentiful resources, low competition and, consequently, high return ratios.

c) Industry concentration. In order to quantify the level of industry concentration, the traditional Herfindahl-Hirshman ( $\mathrm{HH})$ indicator is employed, i.e. the sum of the squared market share held by firms in a particular industry (Kayo \& Kimura, 2011).

R. Rajan and L. Zingales (1995) were probably the first to explore the importance of country-level variables on the financing structure (by examining variables such as: the size of capital markets, bankruptcy law, the link between ownership and control); they argued that these factors do not necessarily act simultaneously with the internal factors of the financial structure.

\section{METHODOLOGICAL LANDMARKS IN SPECIFIC RESEARCH. PERSONAL FINDINGS AND VIEWPOINTS}

For the large majority of specific research, the starting point was the identification of the theoretical 
foundation underpinning the debate; the immediate step is the enumeration of the determinants of capital structure about which certain assumptions are made; to demonstrate the validity or nullity of previously stated assumptions, studies are supplemented by empirical research, involving the development of databases, the implementation of econometric models and the conduct of stress tests.

\subsection{Identifying the theoretical foundations underlying the research}

Three theories stand out in the research field: tradeoff theory, agency theory, and pecking order theory; individually, these theories admit a series of determining factors in relation to which the firm's capital structure (and debt level respectively) are assessed; each of the theories is built on a set of hypotheses in relation to which empirical research aims to position itself (either by confirming or by refuting them).

With reference to the above remarks, we would like to stress that, in making the decision regarding the theoretical foundation, an advance survey of the financing behaviour firms' in the analysed sample must be performed. Out of a desire to conduct research that is as extensive as possible, samples sometimes include firms in several countries and of various sizes, belonging to different business environments, without shared traits in financing behaviour of firms; as a result, grounding the debate on improper theoretical foundations impairs the validity of the findings.

\subsection{Distinguishing the influence factors}

Encapsulating the wide-ranging debates, the determining factors of financial structure have been grouped as follows: a) firm-specific determining factors (asset tangibility; profitability; firm size; growth opportunities; external finance weighted average marketto-book; the probability of financial distress; capital intensity; non-debt tax shields. b) industry-specific determining factors (industry dynamism, concentration and munificence); c) country-specific determining factors (the development of the capital market and the banking system; the legal system; shareholders and creditors' rights; GDP per capita; GDP growth rate; inflation rate; interest rate; tax rate).

With respect to the structure outlined above, we would like to stress that there is no study that examines simultaneously the influence of all these factors on the firm's capital. Therefore, this presents an opportunity for those interested in this area. For the experts, this intention may appear to be inopportune.

It is also worth noting that, due to the diverse environments in which companies do business, one must make a careful selection of influencing factors (which must representative for all the firms in the sample). The tendency that we have noticed is to increase the number of independent variables (influencing factors), which increases the risk of focusing on the impact of sometimes unrepresentative influencing factors. Furthermore, we consider that the identification of influence factors should be done in conjunction with the theoretical foundation adopted a priori.

\subsection{Statement of hypotheses}

Based on the indicators utilised to assess the financial structure, which reflect the total debt levels or debt repayment schedules, hypotheses are formulated which positively or negatively correlate the dependent variables to the independent variables (also estimating their level of significance).

The statement of hypotheses must be undertaken in agreement with the already mentioned financial theories. These are applied in customised manner, as for certain independent variables contradictory hypotheses may be adopted. For instance, as regards the effects of profitability, trade-off theory posits that more profitable firms are exposed to lower financial distress risks and have a stronger incentive to take on debt in order to benefit from tax shields or to increase the firm's performance. Contrary to trade-off theory, pecking order theory is predicated on the idea that more profitable firms favour self-financing to using external sources, profitability being negatively correlated with the leverage effect.

\subsection{Defining the conceptual framework that highlights the link between the capital structure and its determinants}

Although most studies ignore this aspect, we consider it useful to presentat the conceptual framework of analysis, as it enables an overview of the examined phenomena. The all-encompassing approach to the issue of the determinants of firms' capital structure can be rendered, in the most condensed form, as follows (Fig.1.)

\subsection{Operationalisation}

For each variable (dependent/independent) the individual determination methodology is defined; Considering that, in section anterior, we have already presented the methodology used to determine independent variables, here we will present only the methodology employed in determining the dependent variables:

- Total debt ratio = Total debt $/$ Total assets,

- Long-term debt ratio = Long-term debt/(Equity + Debt $)$, - Short-term debt ratio $=$ Short-term debt/(Equity + Debt $)$.

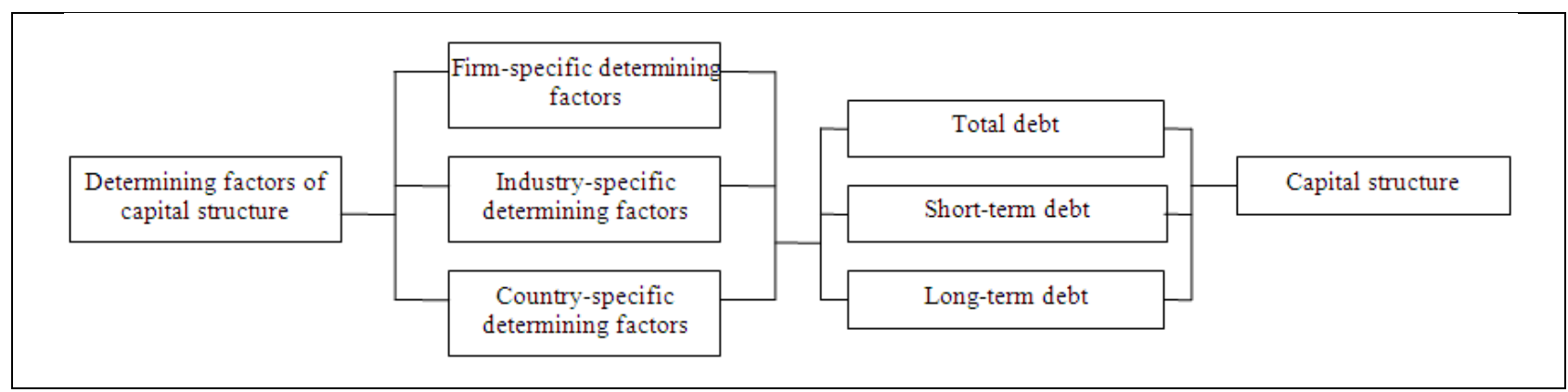

Fig. 1. Conceptual framework of the analysis 
Having reviewed the key works in the field, we have observed that there is no uniform approach on determining (assessing) dependent and independent variables. Nevertheless, in order to ensure the comparability of results, we consider it essential to use common determination methodologies.

\subsection{Establishing the size of the research sample}

Originally, studies of the determining factors of capital structure examined large companies in developed countries. Subsequently, theoretical and empirical studies focused on large firms listed on the stock exchanges in developed and developing countries (without neglecting the specific features of transition countries or emerging markets). As challenges grew and the notion of generalising the results of research was deemed unacceptable, new studies were conducted on smaller, unlisted firms (lacking the same level of access to financial markets). This new level of research first opened up to SMEs in a single country and afterwards expanded its focus to many other countries. The next step was the combined and comparative research.

We are currently witnessing an expansion of the multitude of elements that describe the research sample; this is due to the increase in the number of examined firms, to the more extended period of analysis or to the addition of new influencing factors. Additionally, we would like to stress that the expansion of the investigated sample entails specific risks (such as nonrepresentativeness or the impossibility of comparative analysis of findings). On the other hand, in demarcating the time period of the analysis, one must be aware that, due to the diversity of economic phenomena (both in time and in space), financial, accounting and legal instruments may no longer be applicable to the research process (the analysis being able to capture only some, perhaps non-defining, facets of the system).

\subsection{Identifying the sources forming the database employed in the empirical research}

The design of the data base most often relies on: individual retrieval and processing of data from stock exchange websites; information acquired based on questionnaires/surveys (Campelo et al., 2009); regular statistical reports published by competent bodies (such as the national statistics offices): established databases such as that of those of World Bank, Global Vantage, IFC (International Financial Corporation), WBES (World Business Environment Survey), Worldscope, Global Compustat.

Although there are various alternatives for building the databases, we would like to emphasise that difficulties persist in the observation of the economic phenomenon, its causes and determining factors (which sometimes alter the database).

\subsection{Identifying the nature of the data}

Empirical research on capital structure uses different ways of measuring leverage. These differences result from the specific approach to expressing the valuation of capital; analysing the available studies, we have noted the use of: market value (Balakrishnan \& Fox, 1993; de Jong et al. 2008); book value (MacKay \& Phillips, 2005); combined value: market and book value (Booth et al. 2001, Byoun, 2008; Lemmon et. al., 2008).

With respect to these differences, M.J. Barclay, C.W. jr. Smith and E. Morellec (2006) argue that book leverage would be the most appropriate as it reflects assets in place, not influenced by market variations. Along the same lines, L. Shyam-Sunder and S.C. Myers (1999) assert that market value may distort prospective investment decisions. Moreover, J.R. Graham and C.R. Harvey (2001) suggest that managers do not redefine the structure of capital to reflect changes in equity to market value.

On the other hand, other authors have put forth arguments against using book values, invoking certain rigidities of accounting standards or the size of firms (Welch, 2004). Furthermore, E.K. Kayo and H. Kimura (2011), by using market values to analyse leverage as a dependent variable, estimate that the use of the market value provides a safer perspective on the future debtcarrying potential.

With regard to these divergent views, our opinion is that the distinct research of the two categories of information (either accounting or market-related) may be useful; when analysing listed companies, market values are relevant; nevertheless, when market data are not available or are difficult to obtain, scientists resort to accounting information to complete database. We estimate that using mixed information can alter the representativeness of the findings.

\subsection{Identifying the manner of data presentation to facilitate modelling}

Most researchers use panel data models, based on access to time series of the evolution over a particular period of certain financial indicators; such models consist in estimating regression equations employing series that are simultaneously time series and cross-sectional data. We adhere to the view that the use of panel data is appropriate, as this method enables researchers to: summarise the impact of a variable in a single coefficient (determinant of the capital structure) on a group of time series (dependent variables); estimate specific coefficients (constant or coefficients of independent variables) for each time series considered as a dependent variable; group dependent variables into categories and estimate the impact of the category to which the dependent variable belongs on its evolution.

\subsection{Defining the statistical model}

Researchers use (predominantly linear) statistical models to analyse the importance of the various factors affecting the capital structure (the General Least Squares - GLS method being used particularly often). The model employed to determine the impact of the various variables on leverage can be rendered, in the standard form, as follows:

$$
y_{i t}=\alpha_{i}+\beta X_{i t}^{,}+\varepsilon_{i t}
$$

where: $y_{i t}-$ dependent variable (leverage); $\alpha_{i}-$ individual benchmark for each year; $X_{i t}{ }_{i t}-\mathrm{k}$-dimensional vector of explanatory variables (firm, industry and country-specific variables), $\varepsilon_{i t}$-error term.

Besides the use of multiple linear regression models, we must also point out the use of other (non-linear) 
models, such as the artificial neural networks (ANN). In this respect, a key paper by H. T. Pao (2008), uses models factoring in 7 explanatory firm-specific variables (firm size, growth opportunities, profitability, asset tangibility, non-tax debt shields, dividend payments, business risk) and 3 macroeconomic control variables (capital market, monetary market, inflation rate).

Following relevant assessments, we have noticed on occasion a tendency for a linear model of the economic phenomenon based on the method (even if the economic phenomenon actually follows another pattern of evolution). Therefore, we estimate that an appropriate model must be adopted that provides both a framework and improved prognosis; innovation in modelling (in the field of corporate finance) must be accepted where relevant (already, excessive mathematisation is criticised).

\subsection{Performing the correlation and regression analyses}

The correlation is used to describe the intensity of the link between the two categories of variables (dependent variable - capital structure; independent variable determinants of the capital structure). In most studies, the correlation is examined in order to ascertain the link between the determining factors and capital structure. The level of significance and the coefficient of determination are analysed in addition to the determination of the correlation (which may be positive or negative, weak or intense).

Regression analysis is employed to test the impact of the various influencing factors over the firms' capital structure. It allows quantifying what percentage of the total variation in the financial structure is accounted for by the influence of each separate determinant. In most studies, the regression analysis is followed by a descriptive statistics which lists - in a single table summary information for several variables.

In conclusion, we argue that such analyses are useful for at least two reasons: describing the relationship between two variables and forecasting the values of one in relation to the values of the other (based on the regression equation). Since the ultimate goal of such analysis is forecasting, we emphasise that the quality of predictive formulas depends on the quality of the results of research.

\subsection{Presenting the results}

The implementation of the adopted models yields values that serve to estimate the significance and intensity of correlations. In most cases, each independent analysed variable (i.e. each determining factor specific to the firm, industry or country) is interpreted (individually or linked with other variables) through the prism of the generated results. The results confirm or invalidate previously stated hypotheses. In addition, it is determined whether the results are in accordance with the financial theories considered when formulating the hypotheses.

With regard to the above observations, it is worth emphasising that the sterile interpretation of statistical information obtained is not sufficient; all the other available information must also be considered; in this manner, the financial decision to be adopted will be grounded more soundly, increasing the prospects for delivering an optimised corporate capital structure.

\subsection{Assessing compatibility with previous research}

In order to consolidate the representativeness of results, researchers aim to ascertain the extent to which prior studies yielded similar results. Seeking to assess the compatibility of their own results with previous studies, researchers also check the degree to which the other elements are also comparable (samples, databases, methods employed, adopted theoretical foundations, etc.)

\subsection{Testing the hypotheses}

While it is omitted quite frequently, certain research undertakings devote appropriate attention to this aspect; accordingly, for the purposes of testing the hypotheses, several specific steps are applied in most papers: a) specifying the null hypothesis and the alternative hypothesis; b) identifying the statistical test to be used and its probability distribution; c) stating the test's level of relevance; d) specifying the decision rule (establishing whether the estimated parameter is statistically significant). Finally, the economic decision is formulated, based not only on statistical conclusions but also on all the other available information.

It should be mentioned that due attention should be paid to testing the hypotheses; this is because the development of predictive models, without testing, does not necessarily yield scientific models; rather only the model whose predictions are tested independently becomes scientific.

\section{CONCLUSIONS}

The present study presents the evolution of the theoretical and empirical research on the determinants of firms' capital structure. The identification of the scientific arguments based on which firms' financing mix is established, the proper definition of the benchmarks of the research methodology, the analysis of their architectural structure and the identification of the motives that have driven the development of research were the issues that formed the basis for this study. In light of the above considerations, we consider that the study delivers a threefold utility:

a) scientific, as it presents the state of the art in the field and contributes to the improvement of scientific forecasting methods that enable achieving capital adequacy); the present research allows us to argue that in corporate finance, there are both "false" beliefs (such as the capital structure irrelevance) and verifiable knowledge that takes the form of predictive formulas (research findings being dependent upon their quality); the formulation and testing of logical constructions (assumptions/models/theories) has engaged researchers in wide-ranging debates, enabling or accelerating approaches in new directions; in most cases, research has addressed the need to adapt the capital structure;

b) theoretical and methodological; as regards the theoretical component, the study contributes to grounding and operationalising the determinants of capital structure (including the use of measurable and relevant indicators) and further stresses the importance of this areas of research; as for the methodological utility, it refers to the manner of presenting research methods and techniques of financial structure, the identification and adequacy of working tools and the interpretation of results; by virtue of its design, the study provides a 
framework methodology to undertake further research on the subject;

c) practical, as it can serve as a tool (guideline) for financial decision-makers to optimise their companies' financial structure.

The conclusion we have reached is that, owing to the efforts of researchers, we have witnessed progress in scientific research, accompanied by the application of ever more complex methodologies. This particular development may be attributed to: a) the progress in theoretical research - enabling the emergence of new financial theories (such as the market timing theory); b) the increasing number of independent variables (determining factors) analysed (whereas in the initial stage, research would focus on 4 or 5 firm-specific determinants, currently the number is considerably higher and includes both industry-specific and countryspecific variables); c) the diversification and development of data sources and databases; d) the expansion of the research sample and/or the extension of the period under analysis; e) the contribution of statistics, which has made possible enhanced data processing that facilitates modelling; f) the contribution of econometrics, which has helped to determine new models adjusted to the financial field; g) the growing number of hypotheses whose validity or nullity researchers have undertaken to test; h) concerns regarding the testing/falsification of the results of one's own research.

Through the prism of the evolution of scientific research, we have observed the following: a) the face-off between theory and empirical facts occurs more straightforwardly; b) due to the diversity of economic phenomena (in time and in space), financial, accounting and legal instruments may become inapplicable to the process of scientific research (the analysis being able to capture only certain facets, perhaps non-defining ones, of the system); c) there is still a tendency, on occasion, to rely on linear models to describe the economic phenomenon, based on a particular method (even if the economic phenomenon may follow a different path); d) researchers still face difficulties in observing the economic phenomenon and its causes and determining factors (which sometimes distort the reference databases); e) hypotheses and/or conclusions are not properly tested in all studies, to be refuted by resorting to logic or to factual/empirical assessments.

With regard to the conclusions outlined above, we would like to note that our study lays no claim to being exhaustive; considering that research in the field has proliferated over the years, for the purposes of our undertaking we have focused on a selection of the most representative studies; this limitation notwithstanding, we would like to assure readers that the ideas put forth herein maintain their representativeness.

This study serves as a point of departure for future research. Based on the methodology provided and taking into account the conclusions formulated above, we envisage the opportunity to conduct an empirical study in order to identify and quantify the impact of capital structure determinants on a representative sample of Romanian firms. Developing a model that should facilitate the adequacy of the firm's financial structure will constitute our future research focus.

\section{ACKNOWLEDGEMENTS}

This work was supported by the project "PostDoctoral Studies in Economics: training program for elite researchers - SPODE" co-funded from the European Social Fund through the Development of Human Resources Operational Programme 2007-2013, contract no. POSDRU/89/1.5/S/61755.

\section{REFERENCES}

[1] Baker, M. \& Wurgler, J. (2002). Market timing and capital structure, The Journal of Finance, 57(1), February 2002,, 1-32, ISSN 1540-6261

[2] Balakrishnan, S. \& Fox, I. (1993). Asset specificity, firm heterogeneity and capital structure, Strategic Management Journal, 14 (1), Ianuary 1993, 3-16, ISSN 1097-0266

[3] Barclay, M.J.; Smith Jr., C.W. \& Morellec, E. (2006). On the debt capacity of growth options, The Journal of Business, 79 (1), February 2006, 37-59, ISSN 0021-9398

[4] Bas, T. ; Muradoglu, G. \& Philaktis, K (2010). Determinants of Capital Structure in Emerging Markets, European Financial Management Symposium, First draft, Cass Business School, London, UK

[5] Booth, L.; Aivazian, V.; Demirgüc-Kunt, A. \& Maksimovic, V. (2001). Capital structures in developing countries, Journal of Finance, 56 (1), February 2001, 87-130, ISSN 1540-6261

[6] Byoun, S. (2008). How and when do firms adjust their capital structures toward targets?, The Journal of Finance, 63 (6), December 2008, 3069-3096, ISSN 1540-6261

[7] Campelo, M.; Graham J. R. \& Harvey, C.R. (2009). The real effects of financial constraints: Evidence from a financial crisis, Journal of Financial Economics, 97(3), September 2009, 470478, ISSN 0304-405x

[8] de Jong, A.; Kabir, R. \& Nguyen, T.T. (2008). Capital structure around the world: The roles of firm - and country - specific determinants, Journal of Banking and Finance, 32(9) September 2008, 1954-1969, ISSN 0378-4266

[9] Graham, J.R. \& Harvey, C.R. (2001). The theory and practice of corporate finance. Evidence from the field, Journal of Financial Economics, 60(2-3), May/June 2001, 187-243, ISSN 0304-405x

[10] Hovakimian, A. (2006). Are observed capital structures determined by equity market timing?, Journal of Financial and Quantitative Analysis, 41(1), March 2006, 221-243, ISSN 00221090, EISSN 1759-6916

[11] Kayo, E. K. \& Kimura, H. (2011). Hierarchical determinants of capital structure, Journal of Banking \& Finance, 35(2), February 2011, 358-371, ISSN 0378-4266

[12] Lemmon, M. L.; Roberts, M. R. \& Zender, J. F. (2008). Back to the beginning: Persistence and the cross-section of corporate capital structure, The Journal of Finance, 63(6), Decembre 2008, 1575-1608, ISSN 1540-6261

[13] MacKay, P. \& Phillips, G. M. (2005). How does industry affect firm financial structure?, The Review of Financial Studies, 18 (4), 1433-1466, ISSN 0893-9454, Online ISSN 1465-7368

[14] Myers, S. (2001). Capital structure, The Journal of Economic Perspectives, 15(2), 81-102, ISSN 0895-3309

[15] Pao, H. T. (2009). A comparison of neural network and multiple regression analysis in modelling capital structure, Expert Systems with Application, 35(3), October 2008, 720-727, ISSN 0957-4174

[16] Prahalathan, B. (2010). The Determinants of Capital Structure: An empirical Analysis of Listed Manufacturing Companies in Colombo Stock Exchange Market in SriLanka, Sri Lanka: University of Kelaniya

[17] Rajan, R. \& Zingales, L. (1995). What doweknow about capital structure? Some evidence from international data, The Journal of Finance, 50(5), December 1995, 1421-1460, ISSN 1540-6261.

[18] Shyam-Sunder, L. \& Myers, S.C. (1999). Testing static trade-off against pecking order models of capital structure, Journal of Financial Economics, 51(2), February 1999, 219-244, ISSN 0304-405x

[19] Welch, I., (2004). Capital structure and stock returns. The Journal of Political Economy, 112(1), February 2004, 106-131, ISSN 0022-3808 